\title{
Optimization of Preparation of Zeolite Y Dealuminate Catalysts for Glycerol Conversion to Glycerol Mono Laurate
}

\author{
Didi Dwi Anggoro*, Luqman Buchori, Istadi Istadi, Fadhil R. P., and Antonio G. \\ Department of Chemical Engineering, University of Diponegoro, Semarang 50275, Indonesia
}

\begin{abstract}
This Research has been done to analyze Zeolite Y CBV 712 as a catalyst. Zeolite Y CBV 712 was dealuminated by treating it with $\mathrm{H} 2 \mathrm{SO} 4$ solution, with $3-8 \mathrm{M}$ concentration at $40-60 \mathrm{oC}$. The dealumination treatment runs for 4 hours. Then, dealuminated zeolite was calcinated with a furnace for 3 hours with temperature range between $500-600$ oC. Dealuminated zeolit $Y$ then tested to synthesize Glycerol Mono Laurate (GML). By Analysis of Variance (ANOVA) analyze, indicated that the higher Glycerol Monolaurate yield, X2 factor is the most significance factor, indicating with high Fvalue (29.60768) and low P-value (0.001600). Objective function from this tests, is used to determine the optimum value between dealumination temperature (X1), acid concentration used (X2) and calcinating temperature (X3). The relation between each operating variables and the responses is shown in mathematical equation below :

$$
\begin{aligned}
\text { Yield }(\%)= & -304,099+14,083 X_{1}-0,079 X_{1}^{2}+32,836 X_{2}-2,219 X_{2}^{2}-0,309 X_{3} \\
& +0,001 X_{3}^{2}+0,83 X_{1} X_{2}-0,013 X_{1} X_{3}-0,020 X_{2} X_{3}
\end{aligned}
$$

The optimum condition obtained is $43.250 \mathrm{C}$ for dealumination temperature, $5.45 \mathrm{M}$ for acid concentration and $614 \mathrm{oC}$ for calcination temperature. According to the optimum condition obtained, the glycerol monolaurate yield obtained is $59.470 \%$.
\end{abstract}

\section{Introduction}

One of the glycerol derivative compound is Glycerol Monolaurate which used in food additives, surfactant, medicine, cosmetics and others [1] As a non-ionic surfactant which consists of hydrophilic and hydrophobic group, Glycerol Monolaurate can be used as a nutrition supplement [2]. In the making of Glycerol Monolaurate, catalysts is used to accelerate the reaction and increasing the yield of Glycerol Monolaurate. One of the catalysts that had been used is Zeolite Y [3]. Dealumination is used to increase the acidity of the zeolites [4] Characterization is used to determine the characteristics of the Zeolit Y that had been dealumination [5]. Zeolite $\mathrm{Y}$ is a kind of crystalline aluminosilicate with a microscale cavity which has a pore size of about $0.74 \mathrm{~nm}$ framework [6,7]. The zeolite have the largest application in catalysis and classified as faujasites [8]. Faujasites is a kind of the zeolite mineral group which is a silicate mineral [9].

The previous results [10] showed that the increasing crystallinity percentage represents the higher acid conversion. The higher crystallinity defined decreasing the conversion to GML and GDL from 45.17 to 34.98 for Glycerol Monolaurate (GML) and 31.68 to 20.32 for Glycerol Dilaurate (GDL). Conversion to Glycerol Trilaurate (GTL) had different results. The more crystallinity caused the increasing conversion to GTL from 9.07 to 20.32 . The results indicated that the increasing of crystallinity of zeolite caused the decreasing of the conversion to Glycerol Monolaurate and Glycerol

*Corresponding author : anggorophd@gmail.com 
Dilaurate, except for Glycerol Trilaurate which equal to the percentage of the crystallinity.

In this study, using three stages of chemical treatment processes / dealumination, washing, drying / calcination process. The objective of this study are to determine the optimum value between dealumination temperature $\left(\mathrm{X}_{1}\right)$, acid concentration used $\left(\mathrm{X}_{2}\right)$ and calcinating temperature $\left(\mathrm{X}_{3}\right)$ by using Analysis of Variance (ANOVA) method and to modified Zeolit Y catalysts for produced the Glycerol Monolaurate which higher GML yield.

\section{Experimental Details}

Zeolite Y CBV 712 (supplied by Zeolyst International in $\mathrm{NH}_{4}$ form; mole ratio $\mathrm{SiO}_{2} / \mathrm{Al}_{2} \mathrm{O}_{3}=$ 12; surface area $=730 \mathrm{~m}^{2} / \mathrm{g}$ ) was dealuminated by treating it with $\mathrm{H}_{2} \mathrm{SO}_{4}$ solution. The dealumination treatment was carried out in a three neck flask with stirrer for mixing the sulphuric acid with Zeolite Y, and dealuminated for 4 hours. Then, zeolite that have been dealuminated, calcinated with a furnace for 3 hours. Dealuminated Zeolite $\mathrm{Y}$ then, tested to synthesize glycerol monolaurate using a glycerol and lauric acid, as described at previous paper [10].

\section{Result and Discussion}

The experimental design matrix including the experimental results which is designed using central composite design of response surface methodology are presented in Table 1. The result consists of 16 sets of coded conditions expressed in the natural values. The design consists of eight factorial points, six axial points, three central points. The sequence of experiment was randomized in order to minimize the effects of uncontrolled factors.

Analysis of Variance (ANOVA) used to analyze the Glycerol Monolaurate yield as shown in Table 1 . The significance between each factor in Table 1 was tested using F-value and P-value. High F-value and $\mathrm{P}$-value lower than 0.05 indicating that the variables, significantly influencing the response studied. Fvalue showing the ratio between Mean Square of Factor (MSF) and Mean Square of Error (MSE). The effect of operating variables is shown in Table 1.

Table 1. Analysis of Variance

\begin{tabular}{ccccc}
\hline Variant & Koefisien & F-Value & DF & p-value \\
\hline $\mathrm{X}_{0}$ & $-304,099$ & & & \\
$\mathrm{X}_{1}$ & 14,083 & 9,51471 & 1 & 0,021536 \\
$\mathrm{X}_{1}{ }^{2}$ & $-0,079$ & 8,91520 & 1 & 0,24452 \\
$\mathrm{X}_{2}$ & 32,836 & 3,686619 & 1 & 0,103274 \\
$\mathrm{X}_{2}^{2}$ & $-2,219$ & 29,60768 & 1 & 0,001600 \\
$\mathrm{X}_{3}$ & $-0,309$ & 0,74971 & 1 & 0,419839 \\
$\mathrm{X}_{3}^{2}$ & 0,001 & 0,95074 & 1 & 0,367187 \\
$\mathrm{X}_{1} \mathrm{X}_{2}$ & 0,083 & 0,94272 & 1 & 0,369078 \\
$\mathrm{X}_{1} \mathrm{X}_{3}$ & -0.013 & 9,30101 & 1 & 0,022519 \\
$\mathrm{X}_{2} \mathrm{X}_{3}$ & $-0,020$ & 1,42125 & 1 & 0,278206 \\
\hline
\end{tabular}

As shown in ANOVA table above, for higher Glycerol Monolaurate yield, $\mathrm{X}_{2}$ factor is the most significance factor, indicating with high $\mathrm{F}$-value (29.60768) and low P-value (0.001600). Objective function from this tests, is used to determine the optimum value between dealumination temperature $\left(\mathrm{X}_{1}\right)$, acid concentration used $\left(\mathrm{X}_{2}\right)$ and calcinating temperature $\left(\mathrm{X}_{3}\right)$. The relation between each operating variables and the responses is shown in equation

below:

$$
\begin{aligned}
Y \text { ield }(\%)= & -304,099+14,083 X_{1}-0,079 X_{1}^{2}+32,836 X_{2}-2,219 X_{2}^{2}-0,309 X_{3} \\
& +0,001 X_{3}^{2}+0,83 X_{1} X_{2}-0,013 X_{1} X_{3}-0,020 X_{2} X_{3}
\end{aligned}
$$

Order of this equation is chosen by comparing the coefficient of determination, which the highest coefficient of determination is the most recommended one. Due to this experiment, the highest coefficient of determination $\left(R^{2}\right)$ for the mathematical equation shown above is 91.587.

With high value of coefficient of determination (91.587) indication a match between predicted value and experimental data shown in Figure 1. The linier line in Figure 1 called a regression line. Regression line shows the best prediction between dependent variables (Y) against independent variables (X). However, nature is rarely (if ever) perfectly predictable, and usually there is substantial variation of the observed points around the fitted regression line (Figure 1). The deviation of a 
particular point from the regression line (its predicted value) is called the residual value.

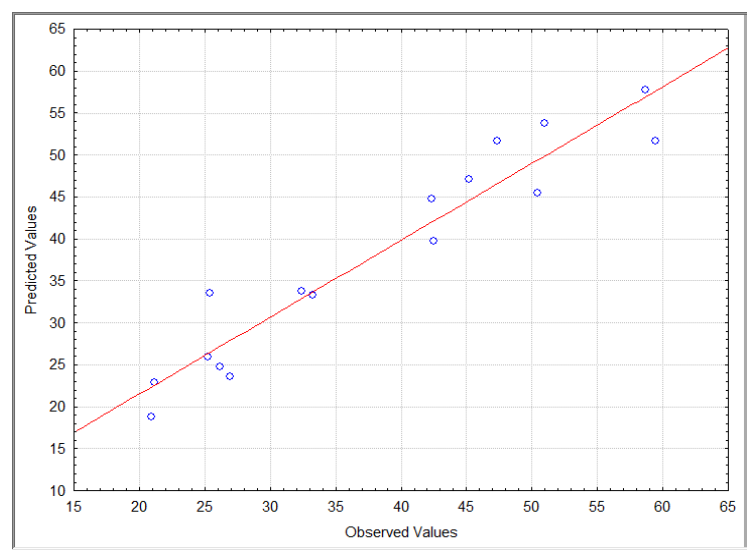

Fig 1. Relation of predicted and observed value of Glycerol Monolaurate yield

Contour plot are the graphical representations of the fitted model that can be used to study the effect of process variables on glycerol monolaurate yield. Figure 2 showed increase in acid concentration used resulting in increasing yield of glycerol monolaurate, increasing acid concentration caused an increasing of glycerol monolaurate yield in the beginning and then achieve an optimal state and then down again. As we can see in Figure 2, the optimal concentration is between 5-6 M, and dealumination temperature between $46-54^{\circ} \mathrm{C}$. Further explanation is given following this paragraph.

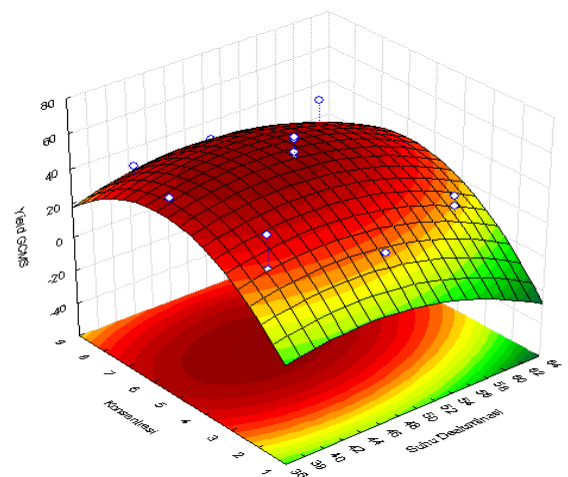

Fig. 2. Contour Plot of Glycerol Monolaurate Yield

Dealumination process is increasing of $\mathrm{Si} / \mathrm{Al}$ ratio in Zeolite $\mathrm{Y}$, and increasing the catalysts ability to synthesize derivate of glycerol becoming glycerol monolaurate (GML), to reach the optimum yield possible. The dealumination temperature, acid concentration and calcination temperature are needed to be control by limiting the operating condition variables.

Optimizing the most significance variables in this research is achieved by using desirability profiling in statistica software. Figure 3 determined that the optimum condition are dealumination temperature is limited within $37-62^{\circ} \mathrm{C}$, acid concentration within 2.2 to $8.7 \mathrm{M}$ and calcination temperature within $485-614^{\circ} \mathrm{C}$.

According Figure 3, the optimum condition obtained is $43.25^{\circ} \mathrm{C}$ for dealumination temperature, $5.45 \mathrm{M}$ for acid concentration and $614^{\circ} \mathrm{C}$ for calcination temperature, which the glycerol monolaurate yield obtained is $59.470 \%$ is obtained. 

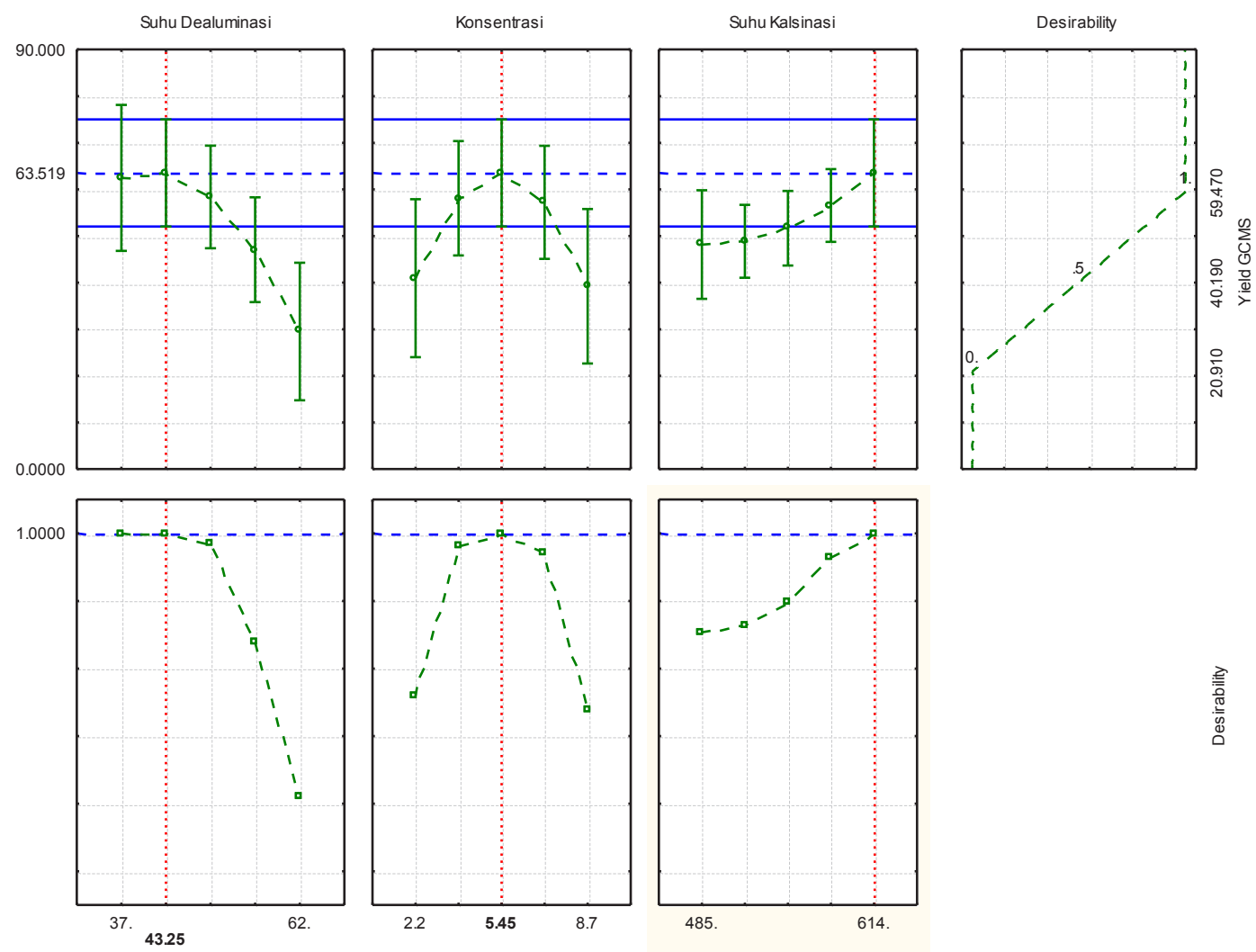

Fig 3. Optimizing Using Responses Desirability Profiling in Statistica 6.0

\section{Conclusion}

The optimum condition obtained is $43.25^{\circ} \mathrm{C}$ for dealumination temperature, $5.45 \mathrm{M}$ for acid concentration and $614^{\circ} \mathrm{C}$ for calcination temperature. According to the optimum condition obtained, the glycerol monolaurate yield obtained is $59.470 \%$. The relation between each operating variables and the responses is shown in mathematical equation below

$$
\begin{aligned}
\text { Yield }(\%)= & -304,099+14,083 X_{1}-0,079 X_{1}^{2}+32,836 X_{2}-2,219 X_{2}^{2}-0,309 X_{3} \\
& +0,001 X_{3}^{2}+0,83 X_{1} X_{2}-0,013 X_{1} X_{3}-0,020 X_{2} X_{3}
\end{aligned}
$$

\section{References}

1. T. Y. Wibowo, A. Z.Abdullah, \& R. Zakaria, Appl. Clay Sci. 50. 280-281. (2010).

2. R. Nakamura, K.Komura, \& Y. Sugi,. Catal. Commun. 9. 511-515. (2008).

3. Y. Wang, R. Otomo, T. Tatsumi, \& T. Yokoi,. Microporous Mesoporous Mater. 220. 275281. (2015).

4. W. Xu, L. Y. Li, \& J. R. Grace,. Chemosphere. 111. 427-433. (2014).

5. M. d. S. Machado, et al. Appl. Catal. 203. 321-328. (2008).

6. B. C. Gates, Catalytic Chemistry. New York:
John Wiley \& Sons, Inc. (1997).

7. Zhao, L. et al. J. Membr. Sci. 498. 1-13. (2015).

8. C. H. Tempelman, et al. Fuel Process. Technol. 139. 248-258. (2015).

9. W. Ratanathavorn, C. Samart, \& P. Reubroychareon,. Mater. Lett. 159. 135-137. (2015).

10. D. A. Didi, B. S. Wahyu, W. Triyogo, B. Luqman, R. P. Fadhil and G. Antonio, Adv. Sci. Lett. 23, 5602-5604 (2017) 